\title{
Treatment of acquired arteriovenous fistula with severe hemodynamic effects: therapeutic challenge
}

\author{
Tratamento de fístula arteriovenosa adquirida com \\ repercussões hemodinâmicas graves: desafio terapêutico
}

Bruna Ferreira Pilan', Andréia Marques de Oliveira', Daniel Emílio Dalledone Siqueira', Ana Terezinha Guillaumon¹

\begin{abstract}
A 34-year-old female patient with severe heart failure and pulmonary hypertension was diagnosed late with a highoutput acquired arteriovenous fistula between the right common iliac vein and artery. The most probable cause was an iatrogenic vascular injury inflicted during a prior laparoscopic cholecystectomy. Treatment was conducted by placement of an endoprosthesis in the common iliac artery, achieving total exclusion of the fistula and complete remission of symptoms. Considering the options available for treating this type of lesion, endovascular techniques are becoming ever more effective and are now the option of first-choice for management of this pathology.
\end{abstract}

Keywords: arteriovenous fistula; endoprothesis; heart failure.

\section{Resumo}

Paciente de 34 anos com quadro de insuficiência cardíaca e hipertensão pulmonar severas, com diagnóstico tardio de fístula arteriovenosa adquirida de alto débito entre a veia e a artéria ilíaca comum direita. A provável causa foi relacionada à lesão vascular iatrogênica em colecistectomia laparoscópica realizada previamente. O tratamento foi realizado com endoprótese em artéria ilíaca comum, resultando em exclusão total da fístula e remissão completa dos sintomas. Considerando-se as opções de tratamento para esse tipo de lesão, a técnica endovascular tem se mostrado cada vez mais eficaz e tem se tornado a primeira opção no manejo dessa patologia.

Palavras-chave: fístula arteriovenosa; endoprótese; insuficiência cardíaca. 


\section{INTRODUCTION}

The most common cause of acquired arteriovenous fistulae (AVF) is rupture of atherosclerotic aneurysms. ${ }^{1}$ Penetrating traumas, including iatrogenic injuries, are responsible for less than $20 \%$ of acquired AVF. ${ }^{2}$ High output AVF, mostly when diagnosis is delayed, can present congestive heart failure symptoms.

\section{PART 1 - CLINICAL SITUATION}

The patient was a 34-year-old female who had already been under cardiologic observation for two years because of progressive dyspnea. She exhibited orthopnea, dyspnea in response to minimal effort and reported frequent hospital admissions because of respiratory decompensation. She also complained of lack of appetite and weakness and had lost 40 $\mathrm{kg}$ in body weight during the previous year. She had undergone videolaparoscopic cholecystectomy five years previously. On physical examination her general state was regular, but she was underweight. Auscultation revealed pansystolic heart murmur and bilateral reduced vesicular murmurs at the base of the lungs. Abdominal examination found ascites, umbilical hernia and hepatojugular reflux with the liver four centimeters from the right costal margin. She also had edema in the lower limbs and a turgid jugular at 45 degrees.

An echocardiogram revealed ejection fraction at $61 \%$, dilation of the vena cava $(36 \mathrm{~mm}$, without respiratory variations), pulmonary hypertension (systolic pressure in pulmonary artery - SPPA - 47 $\mathrm{mmHg}$ ), mild mitral insufficiency, generalized aortic sclerosis with mild insufficiency and generalized increase in cardiac chamber sizes. Magnetic resonance also showed global increase in cardiac chamber size, indirect signs of pulmonary hypertension, bilateral pleural effusion, pericarditis with no sign of constriction and an absence of intracavitary thrombi. Ultrasonography of the abdomen showed moderate/ accentuated ascites, ectasia of the hepatic veins and inferior vena cava with a diameter of $3.9 \mathrm{~cm}$, in addition to hepatosplenomegaly. Pulmonary artery catheterization revealed a SPPA of $54 \mathrm{mmHg}$ and during the procedure, a thrill was detected in the right inguinal region and the right iliac fossa.

In view of these findings, the patient was referred to evaluation by the vascular surgery team.

\section{PART 2 - WHAT WAS DONE?}

The investigation began with an angiotomography, which found an AVF from the right common iliac artery (RCIA) to the right common iliac vein (RCIV), close to the outflow into the cava, in addition to dilation of the inferior vena cava (Figure 1A, $\mathrm{B}$ and $\mathrm{C}$ ), bilateral pleural effusion, ascites and hepatosplenomegaly, all of which had been diagnosed in earlier examinations. It was concluded that the etiology of the AVF was secondary to an iatrogenic injury sustained during insertion of a laparoscopy trocar in the prior videolaparoscopic surgery.

The AVF was corrected using endovascular techniques, by means of placement of a $13 \times 13 \times 80$ $\mathrm{mm}$ endoprosthesis in the RCIA by dissection of the right common femoral artery (Figure 2A, B and C). The thrill had been eliminated by the immediate postoperative period and the patient was kept on full anticoagulation to prevent thrombosis in the ectatic venous system. Anticoagulation provoked a hematoma in the right groin region, which was managed clinically with no need for intervention. The dyspnea and ascites improved progressively.
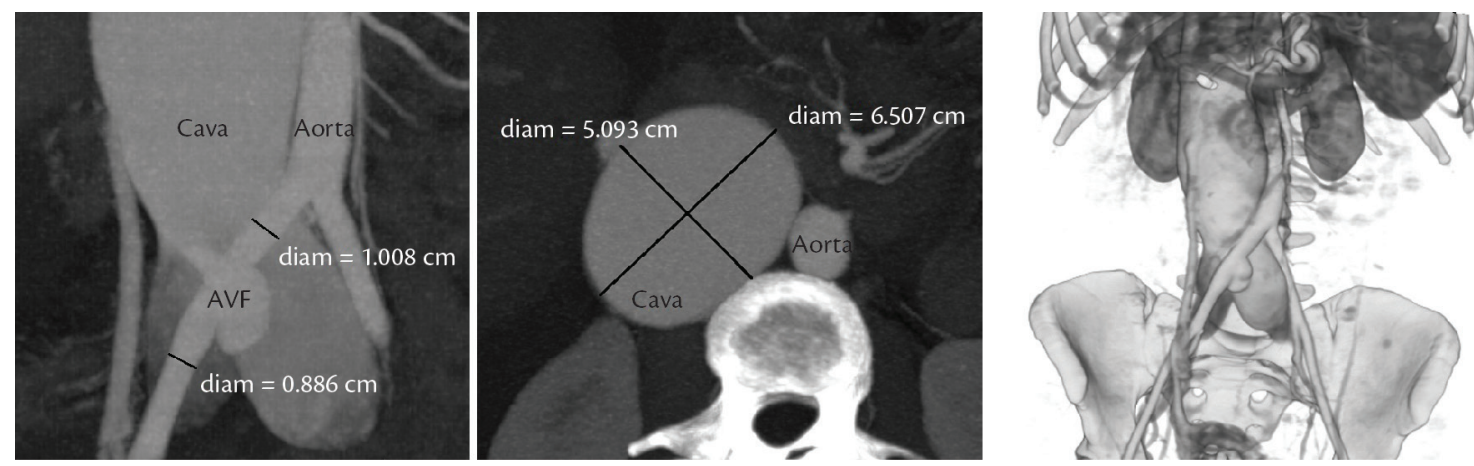

Figure 1. A- Preoperative angiotomography showing presence of an AVF between RCIA and RCIV with contrast in the arterial phase of the vena cava and the iliac veins, which are dilated. Proximal RCIA diam $=1.008 \mathrm{~cm}$; distal $\mathrm{RCIA}$ diam $=0.886 \mathrm{~cm}$, (diam=diameter; $\mathrm{cm}=$ centimeters); B- Axial slice comparing diameters of cava and aorta. Cava diam $=5.093 \mathrm{~cm} \times 6.507 \mathrm{~cm} ; \mathrm{C}-3 \mathrm{D}$ reconstruction of angiotomography. 


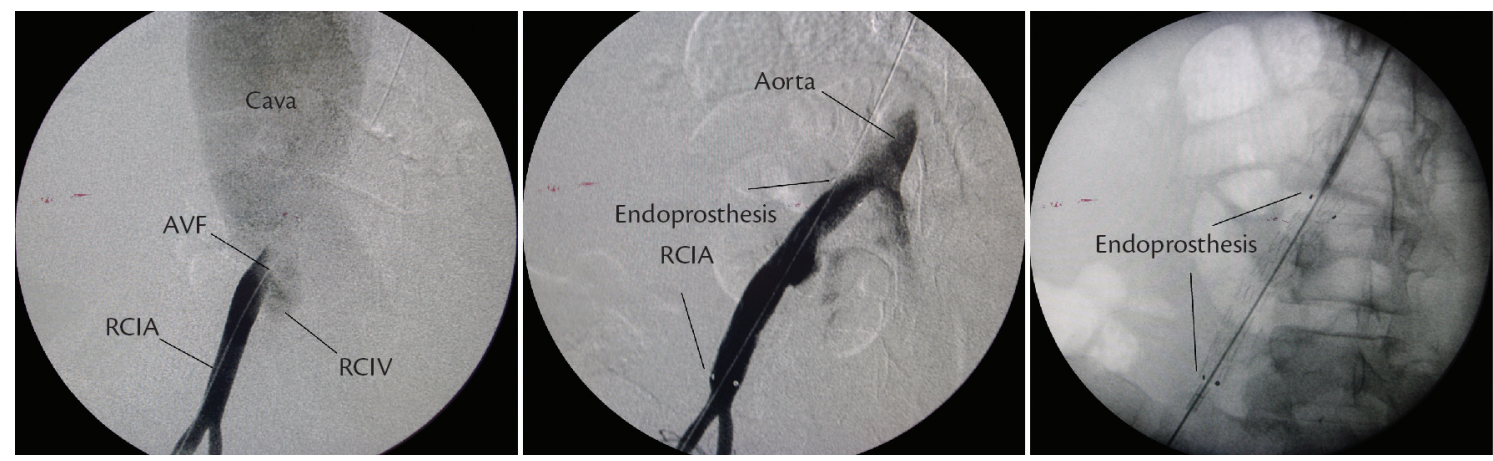

Figure 2. A- Preoperative arteriography with contrast in arterial phase of iliac veins and vena cava; B- Immediate postoperative arteriography showing absence of AVF; C- Endoprosthesis in RCIA.

On the seventh day after surgery, the patient began to show signs compatible with an incarcerated umbilical hernia, which was corrected surgically, with no further intercurrent conditions. She was discharged nine days after the operation on anticoagulation with Rivaroxabana.

At one-month follow-up the patient was eupneic and had enjoyed complete remission from her ascites. After two months, her echocardiogram was normal, with a SPPA of $25 \mathrm{mmHg}$, and Doppler ultrasonography revealed a patent endoprosthesis and no evidence of AVF.

\section{DISCUSSION}

Excluding those created for the purposes of treatment, the majority of acquired AVF occur when an atherosclerotic aneurysm ruptures into an adjacent portion of the venous system, which is a rare event (3 to $4 \%$ of all ruptured aneurysms). Other causes of AVF include syphilitic aneurysms, mycotic aneurysms or aneurysms secondary to Marfan Syndrome, Ehlers-Danlos Syndrome or Takayasu's Arteritis. Vascular injuries have also been described after surgery for herniated discs or secondary to penetrating abdominal traumas or, more rarely, blunt traumas. ${ }^{1}$ This type of injury may be diagnosed a considerable period after onset, in which case they present as venous congestion in the lower limbs, with edema, abdominal pains, heart murmur, congestive heart failure, wide pulse pressure, pulmonary hypertension or attenuated pulses distal to the AVF. ${ }^{2}$

Diagnosis of AVF depends on careful correlation of patient history and a full physical examination. Fistulae may not be diagnosed immediately and some patients present signs or symptoms years later. ${ }^{3}$ In the case described here, the probable cause of AVF was an iatrogenic injury sustained during a laparoscopy procedure five years previously that was not diagnosed at that time. Penetrating traumas, including iatrogenic injuries, are responsible for $20 \%$ of $\mathrm{AVF}^{2}$ Injuries to major vessels during a laparoscopy are rare, affecting less than $0.1 \%$ of patients, ${ }^{4}$ and are generally related to the method used to insert trocars.

AVF that have a late diagnosis can cause significant anatomic and hemodynamic changes. Blood flow increases in the artery proximal to the AVF, which ends up dilating the artery. In extreme cases the artery may become ectatic or aneurysmal. Blood flow is also increased in the vein. The shear stress from arterial flow in the vein leads to thickening or arterializations of the vessel wall in addition to dilation and lengthening. Furthermore, the increase in volume and pressure in the proximal vein causes distal venous flow to slow down, leading to valve incompetence, reverse venous blood flow and venous hypertension. As the fistula grows, certain systemic symptoms may be manifested. The volume of blood in the venous system is increased, which in turn results in an increase in venous return to the heart, reduced peripheral arterial blood pressure and a consequent increase in cardiac output due to higher heart rate and larger systolic volume. This increase in venous blood volume and consequent reduction in arterial blood volume leads to activation of the reninangiotensin-aldosterone system, causing retention of sodium and water. Heart failure sets in when the heart is no longer capable of compensating for this increase in blood volume. ${ }^{5,6}$

For these reasons, patients with AVF often present symptoms of progressive effort dyspnea, heart murmurs and pain. Chronic, high-output AVF can cause heart failure and dilation of the inferior vena cava and the iliac veins, in addition to edema of the lower limbs. The patient described here was in a very severe clinical condition with extreme cardiovascular 
repercussions. However, up to half of patients may not exhibit this classic presentation. ${ }^{7}$

Careful history taking and physical examination are capable of identifying the presence of an AVF; however, additional imaging exams are required, both for confirmation and for localization and treatment planning. Imaging studies make it possible to assess the size of the AVF and its hemodynamic consequences and to determine its relationship with adjacent structures, which is indispensable for planning surgery. ${ }^{5}$ In the case described here, the main exam used for diagnosis and planning was angiotomography and complementary Doppler ultrasonography and arteriography by the time of the surgery.

Once diagnosed, it should be borne in mind that just $2 \%$ of posttraumatic AVF resolve spontaneously. ${ }^{6}$ In fact, the tendency is for these AVF to increase in size, making later repair more complex. Therefore, the mere existence of an acquired fistula is itself an indication for treatment. ${ }^{5}$

From a technical point of view, surgical exposure involved in open repair of late-diagnosed AVF can present serious challenges, due to venous hypertension and inflammation of adjacent tissues, resulting in greater morbidity and mortality. ${ }^{8}$ Large collateral vessels with complex venous anatomy often involve significant blood loss. ${ }^{3}$ Brewster et al. ${ }^{9}$ have reported an operative mortality rate for correction of iliac AVF of 5 to $10 \%$. Davis et al. ${ }^{2}$ documented morbidity of $39 \%$ in surgical corrections of iliac AVF.

In view of this, the less invasive characteristics of endovascular treatment have gained ground and made it the treatment of choice in countless cases., ${ }^{3,5-7,10}$ Placement of endoprostheses within the arterial or venous systems, embolization or a combination of these approaches, ${ }^{7}$ are some of the options available, in addition to thoracic endoprostheses and occluders device. ${ }^{10,11}$ The preferred technique is the implantation of an endoprosthesis that effectively excludes the connection between artery and vein in large caliber vessels, closing off communication and maintaining vascular continuity. ${ }^{3,5}$

The endovascular repair of the traumatic arteriovenous communication using endoprotheses was first described by Parodi in $1992 .{ }^{12}$ Since then, many more authors, including Sanchez et al., ${ }^{13}$ Marin et al., ${ }^{14}$ McCarter et al. ${ }^{15}$ and Zajko et al., ${ }^{16}$ have demonstrated that endoprostheses are effective for treatment of a variety of arterial lesions, including AVF.
Systemic anticoagulation as part of treatment was indispensable to prevent venous thrombosis due to aneurysmal dilatation of the venous system downstream from the AVF and, consequently, to prevent pulmonary thromboembolism.

In addition to the technical success achieved with endovascular treatment of the AVF, both heart failure and pulmonary hypertension were also rapidly and completely reversed. The second of these is linked with mean survival of 2.8 years if left untreated and 1, 3 and 5-year survival rates are 68, 48 and $34 \%$ respectively. ${ }^{17}$

The repair of the high output AVF is the only definitive treatment for secondary congestive heart failure, even when present in one of the severest forms. In the case described here, correction of the AVF changed the course of this patient's survival, since she had terminal congestive heart failure at 34 years of age.

\section{CONCLUSIONS}

Endovascular treatment with an endoprosthesis has proved to be a safe and effective method for correction of high-output acquired AVF and can be considered the treatment of first choice in these patients.

\section{REFERENCES}

1. Pinto DM, Bez LG, Dias JO, Lopes CS, Mandi A. Iliac aneurysm associated with arteriovenous fistula. J Vasc Bras. 2007;6(3):299-302.

2. Davis $P$, Gloviczki $P$, Cherry $K$, et al. Aorto-caval and ilio-iliac arteriovenous fistulae. Am J Surg. 1998;176:115-8. http://dx.doi. org/10.1016/S0002-9610(98)00166-4

3. Queiroz AB, Mulatti GC, Aun R, Valentim LA, Puech-Leão P. Endovascular repair of a traumatic arteriovenous fistula involving the iliac bifurcation using an iliac branch device. J Vasc Surg. 2012 May;55(5):1474-6. Epub 2012 Jan 24. http://dx.doi.org/10.1016/j. jvs.2011.12.006

4. Kuehnl A, Zimmermann A, Pongratz J, Eckstein HH. Young girl presenting with heart failure 5 years after laparoscopic appendectomy. Case report of an ilio-iliac AV fistula. Eur J Vasc Endovasc Surg. 2010 Jul;40(1):107-9. http://dx.doi.org/10.1016/j. ejvs.2010.02.013

5. Sexton JA, Ricotta JJ. Endovascular approaches to arteriovenous fistula. Adv Surg. 2011;45:83-100. http://dx.doi.org/10.1016/j. yasu.2011.03.011

6. Weng CF, Wei J, Lee YT, et al. High-output Heart Failure Resulting from an Obscure Traumatic Arteriovenous Fistula. J Chin Med Assoc 2008;71(8):428-30. http://dx.doi.org/10.1016/ S1726-4901(08)70096-0

7. Wang EA, Lee $M H$, Wang MC, Lee HY. latrogenic left iliaccaval fistula: imaging and endovascular treatment.AJR Am J Roentgenol. 2004 Oct;183(4):1032-4. http://dx.doi.org/10.2214/ ajr.183.4.1831032 
8. Chaudry M, Flinn WR, Kim K, Neschis DG. Traumatic arteriovenous fistula 52 years after injury. J Vasc Surg. 2010 May;51(5):1265-7. Epub 2010 Mar 29. http://dx.doi.org/10.1016/j.jvs.2009.11.080

9. Brewster D, Cambria R, Moncure A, et al. Aortocaval and iliac arteriovenous fistulas: recognition and treatment. J Vasc Surg 1991;13:253-64; discussion 264-5. http://dx.doi. org/10.1016/0741-5214(91)90218-J

10. Cronin B, Kane J, Lee W, Shriki J, Weaver FA. Repair of a highflow iliac arteriovenous fistula using a thoracic endograft.J Vasc Surg. 2009 Mar;49(3):767-70. Epub 2009 Jan 14. http://dx.doi. org/10.1016/j.jvs.2008.10.062

11. Yared K, Baggish AL, Wood MJ. High-output heart failure resulting from a remote traumatic arteriovenous fistula.Can J Cardiol. 2009 Apr;25(4):e143-4. http://dx.doi.org/10.1016/ S0828-282X(09)70083-2

12. Parodi J, Barone $\mathrm{H}$. Transluminal treatment of abdominal aortic aneurysms and peripheral arteriovenous fistulas. In: Proceedings of the 19th Annual Montefiore Medical Center Symposium on Current Critical Problems and New Techniques in Vascular Surgery; 1992; New York. New York; 1992.

13. Sanchez L, Veith F, Ohki T, et al. Early experience with the Corvita endoluminal graft for the treatment of arterial injuries. Ann Vasc Surg 1999;13:151-7. http://dx.doi.org/10.1007/s100169900233

14. Marin $M$, Veith $F$, Panetta $T$, et al. Transluminally placed endovascular stented graft repair for arterial trauma. J Vasc Surg 1994;20:466-72. http://dx.doi.org/10.1016/0741-5214(94)90147-3

15. McCarter D, Johnstone R, McInnes G, Reid D, Pollock J, Reid A. Iliacarteriovenous fistula following lumbar disc surgery treated by percutaneousendoluminal stent grafting. Br J Surg 1996;83:796-7. http://dx.doi.org/10.1002/bjs.1800830622

16. Zajko A, Little A, Steed D, Curtiss E. Endovascular stent-graft repair of common iliac artery-to-inferior vena cava fistula. J Vasc Intervent Radiol 1995;6:803-6. http://dx.doi.org/10.1016/ S1051-0443(95)71190-3

17. McLaughlin VV, McGoon MD. Pulmonary arterial hypertension. Circulation 2006;114(13):1417-31 http://dx.doi.org/10.1161/ CIRCULATIONAHA.104.503540
Correspondence Bruna Ferreira Pilan

UNICAMP - Cirurgia Vascular

Rua Tessália Vieira de Camargo, 126 - Cidade Universitária Zeferino Vaz CEP 13083-887 - Campinas (SP), Brasil Fone: (19) 992460288

E-mail: brunapilan@gmail.com

Author's information

BFP Médica Cirurgiã Vascular, ex-Residente no Serviço de Cirurgia Vascular e Endovascular do Hospital de Clínicas da Faculdade de Ciências Médicas da Universidade Estadual de Campinas - UNICAMP. AMO Médica Cirurgiã Vascular no Serviço de Cirurgia Vascular

e Endovascular do Hospital de Clínicas da Faculdade de Ciências Médicas da Universidade Estadual de Campinas - UNICAMP, Especialista em Cirurgia Vascular pela SBAVC e pela AMB, membro da SBACV.

DEDS Médico Residente de Cirurgia Vascular no Serviço de Cirurgia

Vascular e Endovascular do Hospital de Clínicas da Faculdade de Ciências Médicas da Universidade Estadual de Campinas - UNICAMP.

ATG Professora Associada, Livre-Docente, Chefe da Disciplina

de Moléstias Vasculares da Faculdade de Ciências Médicas da

Universidade de Campinas - UNICAMP e do Serviço de Cirurgia Vascular e Endovascular do Hospital de Clínicas da Universidade de Campinas - UNICAMP, sócia titular da SBACV, sócia da Internacional Union of Angiology, sócia da Society of Vascualr Surgery.

Author's contributions Conception and design: BFP, AMO, ATC Analysis and interpretation: BFP Data collection: DEDS Writing the article: BFP Critical revision of the article: BFP, AMO, ATG Final approval of the article*: BFP, AMO, DEDS, ATC Statistical analysis: N/A Overall responsibility: BFP, ATC Obtained funding: None

*All authors have read and approved of the final version of the article submitted to I Vasc Bras. 